\title{
Continuous Melatonin Attenuates the Regressing Activities of Short Photoperiod in Male Golden Hamsters
}

\author{
${ }^{\dagger}$ Donchan Choi \\ Department of Life Science, College of Environmental Sciences, Yong-In University, \\ Yongin 449-714, Republic of Korea
}

\begin{abstract}
Golden hamsters reproduce in a limited time of a year. Their sexual activities are active in summer but inactive in winter during which day length does not exceed night time and environmental conditions are severe to them. The reproductive activities are determined by the length of light in a day (photoperiod). Melatonin is synthesized and secreted only at night time from the pineal gland. Duration of elevated melatonin is longer in winter than summer, resulting in gonadal regression. The present study aimed at the influences of continuous melatonin treatments impinging on the gonadal function in male golden hamsters. Animals received empty or melatonin-filled capsules for 10 weeks. They were divided into long photoperiod (LP) and short photoperiod (SP). All the animals maintained in LP (either empty or melatonin-filled capsules) showed large testes, implying that melatonin had no effects on testicular functions. Animals housed in SP displayed completely regressed testes. But animals kept in SP and implanted with melatonin capsules exhibited blockage of full regression by SP. These results suggest that constant release of melatonin prohibits the regressing influence of SP.
\end{abstract}

Key words : Melatonin, Golden hamster, Photoperiod, Testis

\section{INTRODUCTION}

Golden hamsters (Mesocricetus auratus) are small mammals who largely inhabit in temperate zone of the Earth (Stetson \& Watson-Whitmyre, 1984). The wild types of those animals are intermediate size between mouse and rat, possessing short and brown coat hair. But some animals show various lengths of coat hair that are short or long in whole body or parts of the body and exhibit diverse colors that are cream, gay, and even white. These animals are favorable to experimental animals and pet animals as well.

Golden hamsters are seasonal breeding rodents whose reproductive activities are active around summer season
(Stetson \& Watson-Whitmyre, 1984; Choi \& Lee, 2012). They avoid the harsh winter environment that are arduous for survival of their offsprings and utilize the climate like summer season for safe fostering of their family in the surroundings with a wealth of food and mild ambiance, averting the likely predators. In the advent of winter their reproductive functions become regressed. Their sexual activities are arrested completely in the winter that are threatening to themselves and their litters. These seasonal breeding strategy is determined by photoperiod that is the length of lighting in a day (Reiter, 1980), which is surmised that the animals can predict possibly annual cycle in a period of a year.

\footnotetext{
Manuscript received 23 May 2013, received in revised form 5 June 2013, accepted 13 June, 2013

${ }^{\dagger}$ Corresponding Author : Donchan Choi, Dept. of Life Science, College of Environmental Sciences, Yong-In University, 134 Yongindaehak-ro Cheoin-gu, Yongin-si, Gyeonggi-do 449-714, Republic of Korea. Tel. : +82-31-8020-2781, Fax : +82-31-8020-2886, E-mail : dcchoi@yongin.ac.kr

This is an Open Access article distributed under the terms of the Creative Commons Attribution Non-Commercial License(http:// creativecommons. org/licenses/by-nc/3.0) which permits unrestricted non-commercial use, distribution, and reproduction in any medium, provided the original work is properly cited.
} 
The fluctuating changes of seasonal reproductive function in the hamsters can be reproduced in the artificial lighting regime. When the reproductively mature hamster males are transferred to short photoperiod (SP; equal to and less than 12 hours in a day), they lose sexual activities regardless of gender. There are no functional spermatozoa in testes and no Graafian follicles in ovaries. If the length of lighting in a day is set to more than 12.5 hours (long photoperiod; LP) like summer season, the sexual functions are energetically maintained and promoted. But if the length of lighting is reduced to SP similar to winter climate, the sexual activities are entirely expelled (Gaston \& Menaker, 1967; Elliott, 1976). The reproductive activities that has been regressed by SP is recovered in a definite period of time when the animals are exposed to LP. Thus, it is known that the light period of 12.5 hours in a day is necessary to sustain the sexual activities in this animal.

Gonadotropin releasing hormone ( $\mathrm{GnRH}$ ) released from the hypothalamus into the pituitary is the utmost element to regulate reproductive function (Bliss et al., 2010). It acts on the gonadotropes to secret gonadotropins, folliclestimulating hormone (FSH) and luteinizing hormone (LH). They are remarkably decreased in animals whose gonads are completely involuted and testosterone in blood is also greatly reduced (Pickard \& Silverman, 1979). Photoperiod regulates the synthesis of melatonin secreting from the pineal gland. The level of blood melatonin is kept low in daytime but is begun to produce in pineal gland at nighttime without artificial light or sunlight. Therefore, the inactivating phenomenon of testicular activity is due to the lengthening of increased melatonin from the pineal gland (Rollag \& Stetson, 1981; Choi, 1996).

The photic signal arrives at the pineal gland by a multistep synaptic course from the photoreceptor located in the retina. An element regulating the synthesis of melatonin is norepinephrine released from the axon terminals of the postganglionic sympathetic neurons present within the pineal gland (Dodge \& Badura, 2001). The pineal gland is subsided at a deep position between cerebrum and cerebellum in human and found at between brain and superior colliculi in golden hamster (Reiter, 1981).

Treatment of melatonin by means of daily injections causes the testes to involute in the evening administration, but not in the morning in the pineal intact animals. These gonadal regression effects are manifest from several hours prior, to 1 hour after lights off and 1 hour before lights on (Stetson \& Tay, 1983). Injections of melatonin at any other time of a day has no effects on testicular function. The results point that there are two windows where melatonin injections will cause testicular regression in pineal intact animals. The outcome is interpreted that the exogenous melatonin is added to the endogenous melatonin. Thus the lengthened period of melatonin resembles winter season, and the animals have involuted testes. Another hypothesis is that there are light sensitive windows that are several hours around lights off and almost 1 hour before lights on. This hypothesis are supported by the skeleton experiments. When the light hits the sensitive window the animals maintain the reproductive functions, but the light does not hit the windows the animals' testes become regressed.

On the other hand, surgical removal of the pineal gland from the hamsters prevents the effects of SP that cause gonadal regression in pineal intact hamsters (Stetson \& Watson, 1984 \& 1986; Grosse et al., 1993). Following the induction of testicular regression by SP exposure, pinealectomy conducts to restoration of generative function, leading to reproductively active status like animals housed in LP. A daily single injection of melatonin in pinealectomized animals does not cause gonadal atrophy. Yet two or three injections of melatonin daily induce testicular involution (Stetson \& Watson, 1986). Thus properly timed daily injections of melatonin to hamsters without pineal gland produce gonadal regression. These results indicate that melatonin likely exert temporal sterile activity through the photoperiodic effects in hamsters.

Another way of administration of melatonin into the animal is to use melatonin infusion or melatonin implants (Maywood et al., 1991). The constant release implants of melatonin prevented gonadal regression in SP-exposed 
golden hamsters. In contrast, similar melatonin implants secreting continuously melatonin induced testicular regression in LP-housed hamsters. Thus melatonin appeared to produce opposite effects, depending on photoperiod. Melatonincontaining capsules implanted before exposure to SP prevented gonadal regression, while the same implants induced gonadal regression in pineal intact animals housed in LP. The results indicate that continuously high levels of melatonin act as an inhibitor of photoperiodic stimulation of reproductive activity and as an inhibitor of photoperiodic inhibition of neuroendocrine gonadal activity. Also it was reported that when melatonin is given by injection in the evening to the animals with melatonin implants, gonadal activity is preserved. The results mean that melatonin can act as a pro-gonadotropic action. At present, it is not likely to generalize how melatonin exerts its effects in hamsters.

The present experiment was designed to test these opposite results mentioned above. Therefore, this study was to demonstrate the changes of reproductive function in golden hamsters, depending on the photoperiod and the constant administration of melatonin.

\section{MATERIALS AND METHODS}

\section{Animals}

The adult male golden hamsters (Mesocricetus auratus) were used in this experiment. They had the period of acclimation for 2 weeks. They were housed in animal breeding boxes within the animal breeding facility in which temperature $\left(22 \pm 1^{\circ} \mathrm{C}\right)$ and humidity $(50 \%)$ were constantly kept. The condition of management of animals was approved by the Yongin University Institutional Animal Care and Use Committee (YUIACUC, 2012-04).

The animal breeding boxes are manufactured with wood, the period of time of lighting was controlled by the timer, external lighting was blocked completely, and ventilation was equipped with the fans. As with the photoperiods, LP consisted of 14 hours of lights and 10 hours of darkness, and SP 10 hours of lights and 14 hours of darkness. The middle point in daytime of each photoperiod was synchronized.
Food and water were provided ad libitum and sanitary management was checked repeatedly.

\section{Photoperiod treatment and experimental procedure}

After acclimation, the golden hamsters were assigned into LP (14L:10D) or SP (10L/14D) as indicated in Table 1. The halves of animals in each photoperiod were implanted with silastic capsules in $33 \mathrm{~mm}$ in length made by medical grade tubing (Dow Corning, inner diameter 0.062 inches, wall thickness 0.017 inches). The animals consisted of 4 groups. They were maintained each photoperiod for 10 weeks. During the period of time the behaviour of animals was observed to examine any abnormal phenomenon because of long-term experiment and body weights and testicular volumes were weighed and measured, respectively, at regular intervals from the beginning of the experiment. The weights of testes were converted from the testicular volumes that was calculated from the measurements of the major axis and the minor axis (Watson-Whitmyre \& Stetson, 1985). At the end of experiment, testicular volumes were measured, were isolated, and were actually weighed to evaluate the weights by calculating from the measured values and real weight values by actual weighing. The spermatogenic analysis was performed by histological examination.

\section{Preparation of melatonin capsules and implantation}

The melatonin capsules were prepared by cutting the medical silastic tubing (Dow Corning, ID $0.062 \times$ wall thickness 0.017$)$. The tubing was cut in $33 \mathrm{~mm}$ and one end was blocked by silicon. After hardening of one end with

Table 1. Experimental groups

\begin{tabular}{cccc}
\hline \hline Name & Photoperiod & Treatment & Note \\
\hline LP Control & LP & Vehicle & \\
LP Melatonin & LP & Melatonin capsule LP: $14 \mathrm{~L} / 10 \mathrm{D}$ \\
SP Control & SP & Vehicle & SP: $10 \mathrm{~L} / 14 \mathrm{D}$ \\
SP Melatonin & SP & Melatonin capsule & \\
\hline
\end{tabular}

LP consisted of 14 hours of lights and 10 hours of darkness, SP 10 hours of lights and 14 hours of darkness. LP; long photoperiod, SP; short photoperiod. 
silicon, melatonin was inserted into the tubing. Then the other end was blocked with silicon, making the capsule. The capsules were left to be hardened at room temperature. The capsules were submerged in alcohol for 1 hour and taken out for drying. The capsules were weighed and followed by implantation. The implantation was performed under full anesthetic narcotism of diethyl ether that acts quickly. The capsules were inserted into the interscapular hypodermis after minimum excising the skin on the midline of back. The excised skin was sutured by using autoclip. When the experiment was over, the capsules were recovered, dried, and weighed to determine the amount of melatonin flowed out.

\section{Determination of testes weights}

The volume of testes was measured by laparotomy. The hamsters were anesthetized using pentobarbital $(25 \mathrm{mg} / \mathrm{kg}$ of body weight) and ketamine ( $50 \mathrm{mg} / \mathrm{kg}$ of body weight). When they were completely anesthetized, laparatomy was performed. After excising the skin overlying the scrotal sac and protruding the testes within the scrotal sac, the major axis and the minor axis of testes were measured by vernier calipers. The skin excised was sutured with surgical thread. The weights of the testes were calculated by the measurements. This method is greatly economic by reducing the animals without killing the many animals. At the end of the experiment, the testes extracted were actually weighed and kept in freezer $\left(-80^{\circ} \mathrm{C}\right)$ until use for histological examination.

\section{Histological examination of testes}

The spermatogenesis of testis was examined by looking at the properly stained slices of testis. Histological examination was performed by using the cryostat (Bright instrument Co., Ltd). The testis kept frozen $\left(-80^{\circ} \mathrm{C}\right)$ was left within the cryostat for more than 30 minutes. The testis was mounted with the embedding medium (Sakura Finetek USA Inc.). The testicular tissue was sliced at 4-6 $\mu \mathrm{m}$ thickness in the animals housed in SP and 12-14 $\mu \mathrm{m}$ thickness in LP, and the slices were laid on the slide glasses. Immediately the slide glasses were put on the slide warmer heated previously into $55^{\circ} \mathrm{C}$ for 30 minutes. After the slide glasses submerged in distilled water for 2 minutes, they were stained with hematoxylin (Sigma) solution for 1 minute. In order to remove excess staining solution, the tissue slides were washed with distilled water for 5 minutes and new distilled water for 2 minutes. After the slides were stained with $0.8 \%$ eosin Y (Sigma) solution for 30 seconds, they were washed in a series of alcohol of $50 \%, 70 \%, 80 \%, 90 \%, 95 \%$ for 1 minute each, then $100 \%$ alcohol twice for 1 minute each. The remained impurities were eliminated by treatment of xylene twice for 2 minutes. The slides were dried entirely to evaporate xylene components and subjected to permanent preparation with canada balsam (Sigma), and finally observed under microscope. The presence and absence of mature spermatozoa, the thickness of the seminiferous tubules, and various germ cells within the tubule were observed and compared with respect to the reproductive functions.

\section{Statistical analysis}

Statistical analysis was performed by using the Student's $t$-test. Data were expressed as means $\pm \mathrm{SD}$, and $p$ value $<$ 0.05 denoted the statistically significant difference.

\section{RESULTS}

\section{Relationship between calculations and real weights}

Fig. 1 shows the relationship between the weight values calculated from the major axis and the minor axis gauged and real weights. The graph turned out to be a positive correlation in relation of real weight measurement on $\mathrm{X}$-axis and calculated values on $\mathrm{Y}$-axis. The correlation coefficient was almost 1 , meaning the perfect correlation that calculations reflect the real weights. Thus in the light of the same organ that calculated and weighed, the weights converted from the volumes were not substantially different from the actual weights weighed. It is enough to understand that there were less numbers of cells present within the organ if it had small volume, or low weight. 


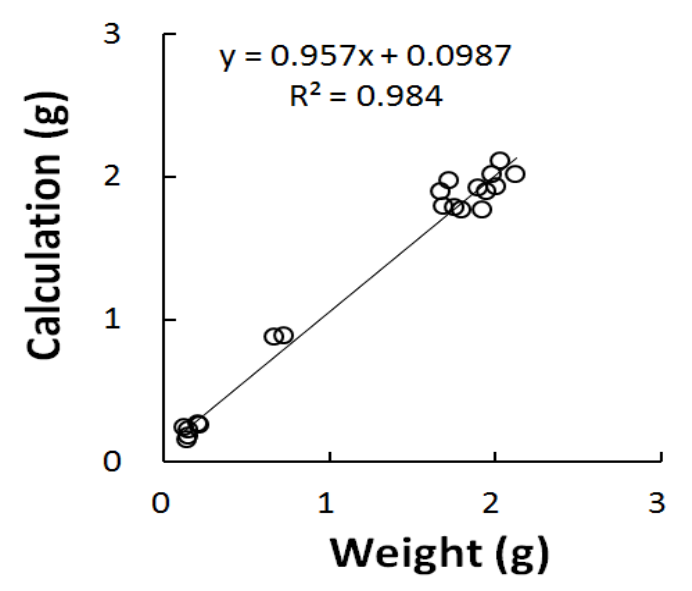

Fig. 1. Correlation of testicular weights. The values on $\mathrm{X}$-axis are real weights and those on Y-axis are weights calculated from the major axis and the minor axis. The correlation coefficient $\mathrm{R}$ is almost 1 and is very close to the intercept on $\mathrm{Y}$-axis. It is noted that the testicular weights converted from the volumes were not substantially different from the actual weights weighed. $(n=20)$.

Therefore, the testes that weigh low by gonadal regression show evidently the abnormal division of germ cells within the testes.

\section{Changes of body weights}

The any deviated changes of body weights and behavior

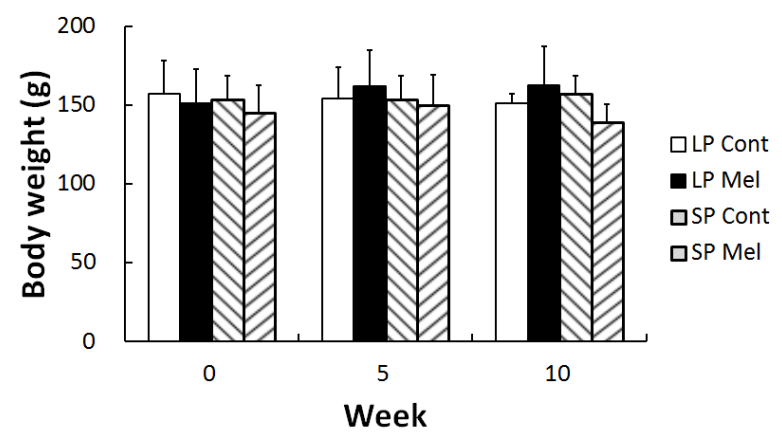

Fig. 2. Changes of body weights. The body weights of golden hamsters were determined at 5 weeks of intervals. It is noted that they were not greatly changed. LP Control; animals housed in LP and implanted with empty capsules, LP Mel; animals housed in LP and implanted with capsules filled with melatonin, SP Control; animals housed in SP and implanted with empty capsules, SP Mel; animals housed in LP and implanted with capsules filled with melatonin. $\mathrm{n} \geqq 3$. of golden hamsters were measured as this study needed long period of time throughout 10 weeks and implanted the melatonin capsules. In results, neither the aberrant behavior was observed nor the body weights of experimental group deviated in comparison to those of control animals (Fig. 2). It was thought that these consequences were possibly due to use of grown-up adults, supported by the diminutive increase of body weights following the beginning of experiment.

\section{Changes of testicular weights}

The animals housed in LP (LP Cont) showed the functional testes all the time. But the animals housed in SP
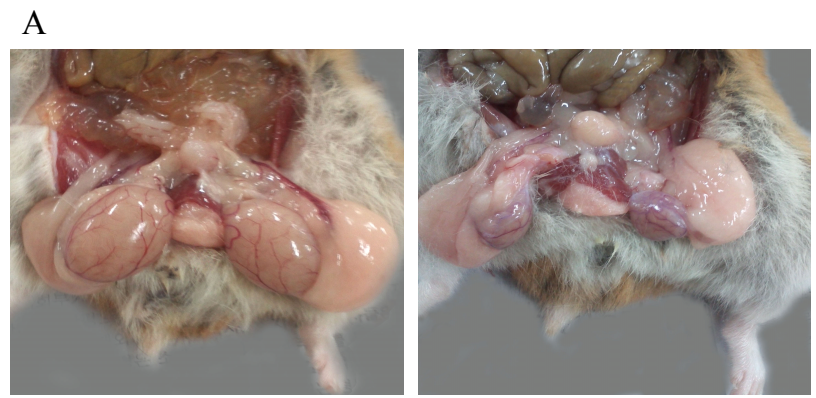

B

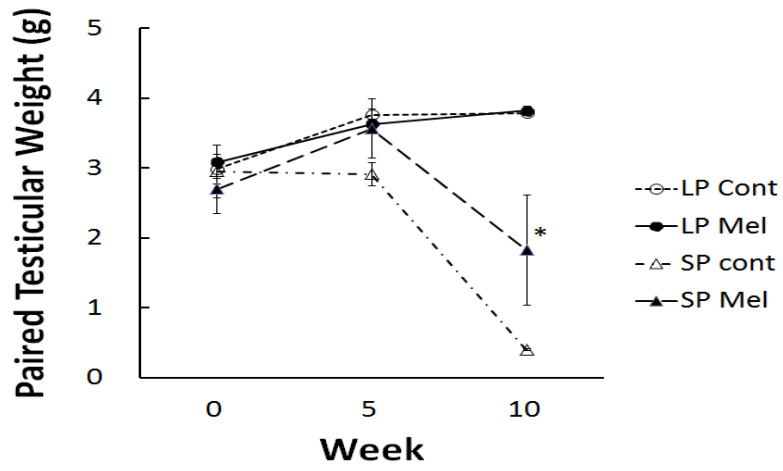

Fig. 3. Changes of testicular mass (A) and summation of weights of left and right testes (B). The testicular weights of golden hamsters were determined at 5 weeks of intervals. It is noted that the testes of animals housed in LP maintained reproductive function (A, left) without respect to melatonin treatment, SP control animals demonstrated distinctly regressed testes in 10 weeks in SP (A, right). The animals kept in SP and implanted with melatonin capsules showed remarkably reduced testicular weights but held reproductive functioning. Asterisk indicates significant differences $(P<0.05)$. As for abbreviation, see Figure 2 . $n \geqq 3$. 
(SP Cont) displayed completely regressed testes in 10 weeks, which are approximately $1 / 8$ in comparison to the initial values (Fig. 3A).

The testicular weights were near $3 \mathrm{~g}$ (summation of left and right testis) in all groups at the beginning of this study (Fig. 3B). The LP animals showed a trend to gradually increase with the melatonin capsules implanted animals (LP Mel). The SP Cont demonstrated remarkably reduced testes in 10 weeks. The testicular weights of animals with melatonin implants in SP (SP Mel) were significantly different from the testes in LP Cont, LP Mel, and SP Cont (Fig. 3B). The results mean that melatonin released from the capsules inhibited the gonadal regression by SP.

\section{Histological examination of testis}

The cells within the testis were observed by light microscope via the histological examination of testis at the end of 10 weeks in each photoperiod (Fig. 4). The large testis showed all kinds of cells involved in spermatogenesis, such as spermatogonium, primary and secondary spermatocytes, spermatids, and spermatozoa, but the regressed testis little cells, spermatogonium, and primary and secondary spermatocytes (Fig. 4). The area of section of seminiferous tubules is diminished into more than one fourth in reproductively inactive animals compared to the reproductively active animals.

In the reproductively active testis, the seminiferous tubules were compacted in relatively oval to circular form when observed with low magnification $(100 \times)$, were close enough each other, were large enough to be mean diameter of $280 \mu \mathrm{m}$. Whereas the seminiferous tubule of regressed testis distributed sparsely in oval to circular style when observed with low magnification $(100 \times)$, were extremely small compared to the testis with reproductive activity, and were to be mean diameter of $160 \mu \mathrm{m}$. Leydig cells were present to be little in relation to the area outside seminiferous tubule of the regressed testis. The cells within the seminiferous tubule in reproductively active and inactive testis were compared in higher magnification $(400 \times)$. The seminiferous tubules of all the animals housed

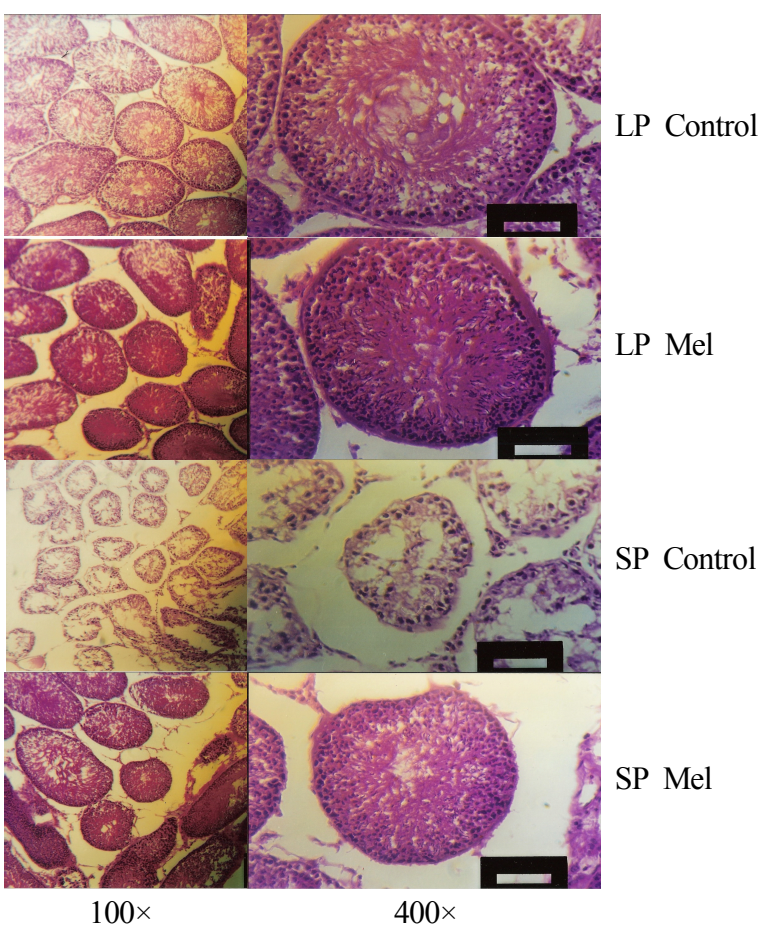

Fig. 4. Histological examination of testis. After treatment for 10 weeks, the testes were isolated and stained with hematoxylin and eosin. All sorts of germ cells involved in spermatogenesis were observed in the testis of animals housed in LP while there were only spermatogonia and little spermatocytes in testis regressed completely due to exposure to SP. Left pictures were enlarged and put at right side. As for abbreviation, see figure 2. Left, 100×; Right, 400×.

in LP and animals implanted with melatonin capsules in SP were full of germ cells, while the seminiferous tubules of testis regressed by SP showed little numbers of germ cells placed at the circumference. The active testis showed spermatogonia at extreme outside, primary spermatocyte a little inside, secondary spermatocyte, spermatid, and spermatozoa at near center and was composed of thick layers of 5-9 thickness of cells.

Large numbers of spermatozoa in lumen of the seminiferous tubules of the sexually active testis were observed and the nuclei of the spermatozoa cells outside the lumen and the tails of the spermatozoa directed to the center of the lumen were visible. On the other hand, all the cells within the seminiferous tubule of testis involuted by SP distributed sparse at the outside of the circumference of the 
tubule. There were spermatogonia at extreme outside, primary spermatocytes a little inside. The secondary spermatocytes, spermatids, and spermatozoa at near center were not observed and the layers of germ cells were reduced and consisted of 2-4 layers.

\section{DISCUSSION}

The testes of animals kept in LP showed functional testes regardless of melatonin treatments. Only animals housed in SP displayed entirely involuted testes. The testes weights in SP Mel animals were partly reduced, but not to the extent of testes of SP Cont animals. The results indicate that continuous release of melatonin partially blocked the regressing effects of SP.

It has been well documented that melatonin reflecting photoperiodic information exerts its effects on the hypothalamo-pituitary gonad (HPG) axis to ultimately regulate the testicular function. The axis is governed by GnRH that is an unique regulator in mammals. On the other hand, the effects of melatonin had been recently informed to be relayed by other factors, which are GnIH and kisspeptin. A hypothalamic factor that inhibited the HPG axis was identified in the quail and called gonadotropin inhibiting hormone (GnIH) (Tsutsui et al., 2000). Since then GnIH has been identified in other aves and found to exert its effects on the GnRH neurons via GPR 147 receptor to control the reproductive endocrine system (Ciccone et al., 2004; Osugi et al., 2004; Yin et al., 2005; Tsutsui et al., 2007; Ubuka et al., 2008). Melatonin also appeared to act directly on $\mathrm{GnIH}$ neurons through its receptor to induce GnIH expression in aves (Ubuka et al., 2005). Thus, it is reasonable to note that melatonin acts indirectly on the GnRH neuronal activity. Chronic treatment of mature birds with $\mathrm{GnIH}$ for 2 weeks decreased plasma testosterone concentrations as well as the synthesis and release of gonadotropins in a dose dependent manner (Ubuka et al., 2006). In golden hamsters GnIH neuronal cell bodies are localized to the dorsomedial hypothalamus, which is a key brain region mediating the influence of melatonin on SP-induced gonadal regression. Whereas long term exposure to inhibitory photoperiod led to the suppression of GnIH immunostaining and mRNA (Revel et al., 2008). Sixty days of melatonin treatment to LD animals showed analogous consequence, indicating that the pineal hormone melatonin mediated these effects. And $\mathrm{GnIH}$ has been reported to inhibit kisspeptin-activated $\mathrm{GnRH}$ firing rate in vitro, indicating the interactions at the cellular level on GnRH target cells.

Kisspeptin was introduced to the reproductive endocrine system in which mutations in kisspeptin receptor are associated with the idiopathic hypothalamic hypogonadism (de Roux et al., 2003; Lee \& Choi, 2005). Moreover, the kisspeptins and their specific receptor GPR54 represented the potent stimulators of the sexual axis. Melatonin showed strong impact on kisspeptin gene expression in the Syrian hamster. Kisspeptin gene was expressed in the anteroventral-periventricular and arcuate nuclei of the hypothalamus at significantly higher levels in hamsters kept in LP as compared to SP (Revel et al., 2007). In the arcuate nucleus, the down-regulation of kisspeptin gene expression in SD appeared to be mediated by melatonin and not by secondary changes in gonadal hormones. And a chronic administration of kisspeptin restored testicular activity in SP hamsters, despite persisting photoinhibitory conditions. The major crucial elements involved in the mechanism of seasonal reproductive system are enlarged by addition of $\mathrm{GnIH}$ and kisspeptin, impinging directly on the utmost important GnRH neurons. Overall, melatonin is considered to modulate kisspeptin gene neurons to drive the reproductive axis.

There is another intriguing speculation about relevance of melatonin, corticotropin-releasing hormone, and their receptors present in both hamster testes and testes of infertile men in biopsy (Rossi et al., 2012).

On the basis of findings reported to date, these two neuropeptides ( $\mathrm{GnIH}$ and kisspeptin) play key roles in reproduction. It is reasonable to surmise that kisspeptin and GnIH serve to work on the pathway of excitatory and inhibitory signals in the regulation of HPG axis. Their 
interaction is now of importance to pursue the integrative understanding of seasonal reproduction.

The animals inhabiting in the periodic changes of day and night show the rhythmic levels of melatonin. Whatever the mechanism involved in the regulation of reproduction in seasonal breeders such as golden hamsters, the level of melatonin is very low in day time and high at night. It has been substantiated that the duration of melatonin secretion determines the reproductive function. Thus the reproductive activity is active in LP displaying the short duration of melatonin release such as summer season and inactive in SP the long duration of melatonin release like winter climate. If there are always constant existence of melatonin, the animals can not discern the lengths of day and night. Then the animals may regard the constant presence of melatonin (no rhythmic fluctuation in a day) as constant lightening environment, which lead to sexually active function.

Taken these various outcomes together, the information of photoperiod is known to be transmitted into the reproductive endocrine system via the aspects of rhythmic melatonin secretion coming from the pineal gland. Allowing that the key element regulating reproduction is GnRH secreting from the hypothalamus, the photoperiodic information via melatonin mediation is directly or indirectly considered to regulate the reproductive function by exerting its effects on GnRH neurons. The present study demonstrates that the testicular regressing process of SP is suppressed in golden hamsters if there is constantly high levels of melatonin. Further investigation is required to understand the active mechanism of rhythmic presence of melatonin in this golden hamster.

\section{ACKNOWLEDGMENT}

This research was supported by a research grant from Yong-In University (2012).

\section{REFERENCES}

Bliss SP, Navratil AM, Xie J, Roberson MS (2010) GnRH signaling, the gonadotrope and endocrine control of fertility. Neuroendocrinology 31:322-340.

Choi D (1996) Reproductive physiology of pineal hormone melatonin. Korean J Zool 39:337-351.

Choi D, Lee S-H (2012) Neuroendocrine system in seasonal breeder: focusing on the reproductive activity of male golden hamster. Dev Reprod 16:1-8.

Ciccone N, Dunn IC, Boswell T, Tsutsui K, Ubuka T, Ukena K, Sharp PJ (2004) Gonadotrophin-inhibitory hormone depresses gonadotrophin alpha and follicle stimulating hormone beta subunit expression in the pituitary of the domestic chicken. J Neuroendocrinol 16:999-1006.

de Roux N, Genin E, Carel JC, Matsuda F, Chaussain JL, Milgrom E (2003) Hypogonadotropic hypogonadism due to loss of function of the Kiss-1 derived peptide receptor GPR54. Proc Natl Acad Sci USA 100:1097210976.

Dodge J, Badura LL (2001) Norepinephrine dialysate levels in the hypothalamic paraventricular nucleus: influence on photoperiod-driven prolactin levels in the female Siberian hamster. Neuroendocrinol 73:102-110.

Elliott JA (1976) Circadian rhythms and photoperiodic time measurement in mammals. Fed Pro 35:23392346.

Gaston S, Menaker M (1967) Photoperiodic control of hamster testis. Science 158:925-928.

Grosse J, Maywood ES, Ebling FJP, Hastings MH (1993) Testicular regression in pinealectomized Syrian hamsters following infusions of melatonin delivered on noncircadian schedules. Biol Reprod 49:666-674.

Lee SH, Choi D (2005) KiSS-1: A novel neuropeptide in mammalian reproductive system. Dev Reprod 9:1-5. Maywood ES, Lindsay JO, Karp J, Power JB, Williams LM, Titchener L, Ebling FJP, Herbert J, Hasting MH (1991) Occlusion of the melatonin-free interval blocks the short day gonadal response of the male Syrian hamster to programmed melatonin infusions of necessary duration and amplitude. J Neuroendocrinol 3:331-337. Osugi T, Ukena K, Bentley GE, O'Brien S, Moore IT, 
Wingfield JC, Tsutsui K (2004) Gonadotropin-inhibitory hormone in Gambel's white-crowned sparrows: cDNA identification, transcript localization and functional effects in laboratory and field experiments. J Endocrinol 182: $33-42$.

Pickard GE, Silverman AJ (1979) Effects of photoperiod on hypothalamic luteinizing hormone releasing hormone in the male golden hamster. J Endocrinol 83:421-428.

Reiter RJ (1980) Photoperiod: Its importance as an impeller of pineal and seasonal reproductive rhythms. Int $\mathrm{J}$ Biometeorol 2457-2463.

Revel FG, Ansel L, Klosen P, Saboureau M, Pévet P, Mikkelsen JD, Simonneaux V (2007) Kisspeptin: a key link to seasonal breeding. Rev Endocr Metab Disord. 8:57-65.

Revel FG, Saboureau M, Pevet P, Simonneaux V, Mikkelsen JD (2008) RFamide-related peptide gene is a melatonin driven photoperiodic gene. Endocrinology 149:902912.

Rollag MD, Stetson MH (1981) Ontogeny of the pineal melatonin rhythm in golden hamsters. Biol Reprod 24:311-314.

Rossi SP, Matzkin ME, Terradas C, Ponzio R, Puigdomenech E, Levalle O, Calandra RS, Frungieri MB (2012) New insights into melatonin/CRH signaling in hamster Leydig cells. Gen Comp Endocrinol 178:153-163.

Stetson MH, Tay DE (1983) Time course of sensitivity of golden hamsters to melatonin injections throughout the day. Biol Reprod 29:432-438.

Stetson MH, Watson-Whitmyre M (1984) Physiology of the pineal and its hormone melatonin in annual reproduction in rodents. In "The Pineal Gland" edited by Reiter RJ, Raven Press, New York, pp 109-153. Stetson MH, Watson-Whitmyre M (1986) Effects of exogenous and endogenous melatonin on gonadal function in hamsters. J Neural Transm 21(Suppl):55-80.

Tsutsui K, Bentley GE, Ubuka T, Saigoh E, Yin H, Osugi T, Inoue K, Chowdhury VS, Ukena K, Ciccone N, Sharp PJ, Wingfield JC (2007) The general and comparative biology of gonadotropin-inhibitory hormone $(\mathrm{GnIH})$. Gen Comp Endocrinol 153:365-370.

Tsutsui K, Saigoh E, Ukena K, Teranishi H, Fujisawa Y, Kikuchi M, Ishii S, Sharp PJ (2000) A novel avian hypothalamic peptide inhibiting gonadotropin release. Biochem Biophys Res Commun 275:661-667.

Ubuka T, Bentley GE, Ukena K, Wingfield JC, Tsutsui K (2005) Melatonin induces the expression of gonadotropininhibitory hormone in the avian brain. Proc Natl Acad Sci USA 102:3052-3057.

Ubuka T, Kim S, Huang Y, Reid J, Jiang J, Osugi T, Chowdhury VS, Tsutsui K, Bentley GE (2008) Gonadotropin-inhibitory hormone neurons interact directly with gonadotropin-releasing hormone-I and -II neurons in European starling brain. Endocrinology 149:268-278.

Ubuka T, Ukena K, Sharp PJ, Bentley GE, Tsutsui K (2006) Gonadotropin-inhibitory hormone inhibits gonadal development and maintenance by decreasing gonadotropin synthesis and release in male quail. Endocrinology 147: 1187-1194.

Watson-Whitmyre M, Stetson MH (1985) A mathematical method for estimating paired testes weight from in situ testicular measurements in three species of hamster. Anat Rec 213:473-476.

Yin H, Ukena K, Ubuka T, Tsutsui K (2005) A novel G protein-coupled receptor for gonadotropin-inhibitory hormone in the Japanese quail (Coturnix japonica): Identification, expression and binding activity. J Endocrinol 184:257-266. 